\title{
Benefits and challenges of collaborative research: lessons from supportive and palliative care
}

\author{
Sheila Payne, Jane Seymour, ${ }^{2}$ Alex Molassiotis, ${ }^{3}$ Katherine Froggatt, ${ }^{1}$ Gunn Grande, ${ }^{3}$ \\ Mari Lloyd-Williams, ${ }^{4}$ Claire Foster, ${ }^{5}$ Roger Wilson, ${ }^{1}$ Liz Rolls, ${ }^{1}$ Chris Todd, ${ }^{3}$ \\ Julia Addington-Hall ${ }^{5}$
}

${ }^{1}$ School of Health and Medicine, Lancaster University, Lancaster, UK ${ }^{2}$ School of Nursing, Midwifery and Physiotherapy, University of Nottingham, Nottingham, UK

${ }^{3}$ School of Nursing, Midwifery and Social Work, University of

Manchester, Manchester, UK

${ }^{4}$ School of Population,

Community and Behavioural

Studies, University of

Liverpool, Liverpool, UK

${ }^{5}$ School of Health Sciences,

University of Southampton,

Southampton, UK

\section{Correspondence to}

Professor Sheila Payne,

School of Health and Medicine, Lancaster University,

Lancaster LA1 4YT, UK;

s.a.payne@lancaster.ac.uk

Accepted 11 April 2011

\section{ABSTRACT}

Objective To describe the processes of establishing and running the Cancer Experiences Collaborative (CECo), and reflect upon the benefits and challenges of undertaking collaborative research in supportive and palliative care.

Design A descriptive analysis of a 5-year research collaborative initiated in 2006.

Setting Research groups at the Universities of Lancaster, Liverpool, Manchester, Nottingham and Southampton, England.

Participants 26 UK organisations including the four largest hospices in England, hospital cancer centres, Help the Hospices (a national charity supporting independent hospices) and user representatives.

Findings The aim of CECo was to enhance the value, quality and productivity of scientific research in supportive and palliative care, and to increase research capacity and improve the coordination of collaborative research. Three programmatic themes of research were established: (i) innovative approaches to complex symptoms, (ii) planning for the care of older adults towards the end of life and (iii) research methodology including narrative approaches. Four benefits and challenges are highlighted: strategic leadership and management structures for cross-institutional work, working in multidisciplinary groups and linking research with practice settings, capacity building, and user involvement.

Conclusions The activities of CECo have resulted in significant benefits with an increase in good quality research studies that have led to the production of a significant number of peer-reviewed papers, and learning between academics, clinicians and users, which has contributed to raising the standards of supportive and palliative care research. However, the future of such research initiatives is fragile, with concerns about the sustainability of collaboration in the face of diminishing resources.

\section{INTRODUCTION}

The purpose of this paper is to share our experiences of the benefits and challenges of collaborative research, a model of working used by the Cancer Experiences Collaborative (CECo) which is a large 5-year research collaborative initiated in 2006 to improve supportive and palliative care research in the UK. Supportive and palliative care is a "data-poor field", and the National Cancer Research Institute (NCRI) strategic review of UK supportive and palliative care research identified serious weaknesses in this area. ${ }^{2}$ To address these, the NCRI recommended the establishment of interdisciplinary supportive and palliative care research collaboratives to include academic organisations, researchers, and individuals and groups from different research disciplines and clinical professions. Their purpose would be to enhance the value, quality and productivity of UK research in all aspects of cancer-related supportive and palliative care. ${ }^{3}$ Following a competitive process, CECo was one of two collaboratives awarded funding for a period of 5 years during which it has developed into a flourishing, interdisciplinary, research community. There have been many benefits, and a number of significant challenges as a result of creating and sustaining a research-focused initiative that has brought together disparate groups, developed innovative research and built research capacity, and begun to influence policy and practice in cancer and other illness-related supportive and palliative care.

There are previous examples of successful research collaborations such as the European Organisation for Research and Treatment of Cancer (http://www.eortc.be), which aims to improve the standard of cancer treatment by developing, conducting, coordinating and stimulating translational and clinical research in Europe. There are also a number of collaborative groups who focus on specific topics such as hormonal factors in breast cancer ${ }^{4}$ or prostate cancer. ${ }^{5}$ The purpose of these collaboratives has been to test more effective therapeutic strategies, accomplished mainly by recruiting to, and conducting large, multicentre, prospective, randomised, phase III clinical trials. There are also an increasing number of international collaborative research initiatives in palliative care such as research networks in North America and in Europe. For example, the European Union (EU) Sixth and Seventh Frameworks and other funded studies have started to address clinical and organisational aspects of palliative care including symptom management in advanced cancer (EPCRC 2006), organisational indicators in palliative care (EUROPALL 2007), clinical outcomes measurement and cultural diversity (PRISMA 2008), care in the last days and hours of life (OPCARE9 2008), access to pain medication (ATOME 2009) and research into palliative sedation (UNBIASED 2010). The European Palliative Care Research Centre, based in Trondheim, Norway, focuses predominantly on clinical and translational research in palliative care. An EU 
Marie Curie Initial Training Network-funded initiative (EURO IMPACT 2010) aims to train 12 early stage and six postdoctoral researchers in palliative care to increase research capacity and inter-sectorial mobility. Therefore the Supportive and Palliative Care Research Collaboratives in the UK contribute to wider developments to increase research quality and capacity, but unlike the majority of the EU funded projects, funding was explicitly for intra-structure support rather than to conduct research projects.

\section{CECO}

CECo was established as a partnership between researchers at five UK universities (Lancaster, Liverpool, Manchester, Nottingham and Southampton) and 26 other UK organisations including the four largest hospices in England, hospital cancer centres, Help the Hospices and user representatives. The purpose was to improve the quality and quantity of palliative and supportive care research. In its response to the identified shortcomings, CECo developed a set of aims designed to increase and enhance both high quality quantitative and qualitative research, and research capacity in the extended field of supportive and palliative care (box 1). Where appropriate we have presented evidence of indicators of achievement against our aims, but the main purpose of this paper is to draw out lessons on the process of collaboration in research rather than to report on the outcomes of CECo; such a paper will be forthcoming after completion of Year 5.

\section{CECo's dimensions of work}

To meet these aims, three dimensions of work were identified: enhancing research, building research capacity and increasing user involvement.

\section{Enhancing research}

CECo generated research concerned with developing and testing effective solutions using optimal research designs under three themes: (i) innovative approaches to complex symptoms, (ii) planning for the care of older adults towards the end of life and (iii) research methodology including narrative approaches. Further details are available on the CECo website (http://www.ceco.org.uk).

\section{Building research capacity}

To enhance current research work and to ensure the future sustainability of research in supportive and palliative care, CECo placed great emphasis on improving both the quality and quantity of researchers through capacity building. Key dimensions included developing a basic understanding and appreciation of research among clinicians, promoting evidence-based practice to benefit patient care, and giving talented individuals

\section{Box 1 Aims of the Cancer Experiences Collaborative}

Develop new methodologies and approaches to address clinical challenges in supportive and palliative care research (including how best to meet the needs of patients, their families and carers; increase research capacity) Improve the quality of the research

- Maintain a clear focus on policy and practice

Support new researchers, and do so in a way that ensures that progress is maintained the opportunity to pursue research projects through expert mentorship and research scholarships.

\section{Increasing user involvement}

Users - understood as "people who receive or are eligible to receive... services"6 - included patients, family carers, health and social care professionals, support workers, members of voluntary organisations and advocacy groups, and members of the public, all of whom were central to CECo's activities. These people chose to be called 'research partners' in recognition of the subtle shift through which they became integral to the whole process of research rather than just included in parts of it. Participation was funded by an independent budget, and research partners contributed by participating in CECo management, advising on CECo scholarship awards and reviewing and advising on all aspects of CECo research, for example, helping to refine research questions, developing new measures grounded in first-hand experience and improving the quality of information for research participants. Training for research partners included a series of learning activities about research, committee and academic procedures, and two universities developed an active 'Research Partner Forum'.

\section{THE BENEFITS AND CHALLENGES OF COLLABORATIVE WORKING}

Establishing and maintaining CECo as an interdisciplinary, cross-institutional research collaborative was predicated on four key elements: strategic leadership and management structures for cross-institutional work, working in multidisciplinary groups and linking with practice settings, capacity building, and user involvement. Each of these resulted in significant benefits, but also involved a number of challenges that needed to be addressed.

\section{Strategic leadership and management structures for cross-institutional work}

Central to the success of CECo was the development and maintenance of two key dimensions: strategic leadership and appropriate management structures for cross-institutional work (see figure 1). Strategic direction and leadership were provided by the CECo Executive Group, which included the Co-Directors, senior representatives from the five CECo universities, Research Theme leaders, a Capacity Building lead and an experienced service user representative. The executive group undertook internal monitoring of activity, managed the overall budget and reported annually to NCRI. In addition, critical appraisal of performance and guidance on strategy were received from independent advisors from the UK and Europe.

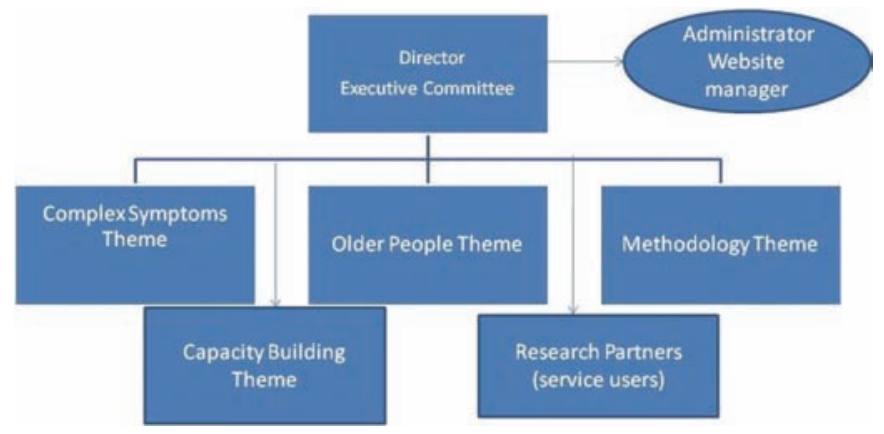

Figure 1 Organisational management structure for the Cancer Experiences Collaborative. 
Operational management of the day-to-day aspects of the complex work was originally through a central management system, but responsibility and budgets were later devolved to the Research Theme leaders, making it possible to utilise the broad range of skills and experiences available within the Collaborative more effectively and collegiately. Research Theme leaders were responsible for providing academic leadership and ensuring that objectives were met, and, together with a small team of supportive and palliative care researchers, were responsible for taking forward CECo's programme of collaborative research development, research capacity building activities and other events consistent with each Research Theme's special remit.

Because of the breadth and complexity of the Collaborative, the creative use of technology was crucial for developing cohesion, maximising opportunities for good communication and enhancing efficient and rapid decision-making. Meetings were often held through conference calls, and the development of the research community was facilitated through the provision of a website that provided increasingly sophisticated facilities for joint working. An online forum enabled researchers, service users and clinicians to contribute to collaborative projects, engage in discussion and keep up to date.

The benefits of this leadership effort included staff from across the individual institutions having a shared vision and an allegiance to a larger entity (the Collaborative), the smooth running of projects, good communication between researchers, clinicians, users and institutions, and capacity building at all levels. However, the challenge of finding a way to manage people, resources and research projects across organisations and disciplines was considerable.

The management of people relied on the exercise of good leadership, and we initially underestimated the labour-intensive and time-consuming demands that would be placed on the Co-Directors and leaders to achieve stability and manage change. In the absence of normal line-management responsibility, considerable time was spent developing governance arrangements and managing people and projects effectively across institutions. Moreover, in order to enable members to risk venturing outside of comfortable peer groups to share ideas and resources, and to motivate them to make and maintain strong links between researchers, practitioners of supportive and palliative care, and patients and their families, it was essential to engage and maintain a shared vision of the potential benefits of collaboration over a long period of time. This was especially challenging when there was a heavy reliance on the good will of individuals, and on motivating people with different expectations that required assimilating and for whom the benefits were uncertain. The management of funding and resources was also a problematic issue, especially as initially no resource was provided to release senior staff from their existing university commitments. Furthermore, research contracts were awarded to a lead centre, which had the potential to create tensions inconsistent with collaboration. CECo directors worked hard to agree allocation of resources but, nevertheless, an unequal distribution remained, with not everyone having equal access to budgets. In addition to the central funding issue, there were opportunity costs for those individuals in the team who wrote new research proposals and provided mentorship. Finally, the cross-institutional management of research required considerable endeavour beyond customary research project management. In the first instance, CECo staff were often having to build relationships with former competitors and, unlike other collaboratives, were managing more than one research project. CECo staff had to negotiate and develop 'rules' to guide commissioning research activities. Furthermore, as well as facilitating collaborative activities, managing research projects and organising researchrelated events, a considerable amount of staff time was taken in mentorship of research fellows not only within the same university but also in other institutions. Nevertheless, despite these difficulties, and because of a strong sense of commitment to the vision of CECo, these challenges have largely been negotiated or assimilated.

\section{Working in multidisciplinary groups and linking research with practice settings}

CECo placed great emphasis on multidisciplinary research, and people worked hard to develop mutual trust, co-operation and skill-sharing, and the integration of activities across the wide

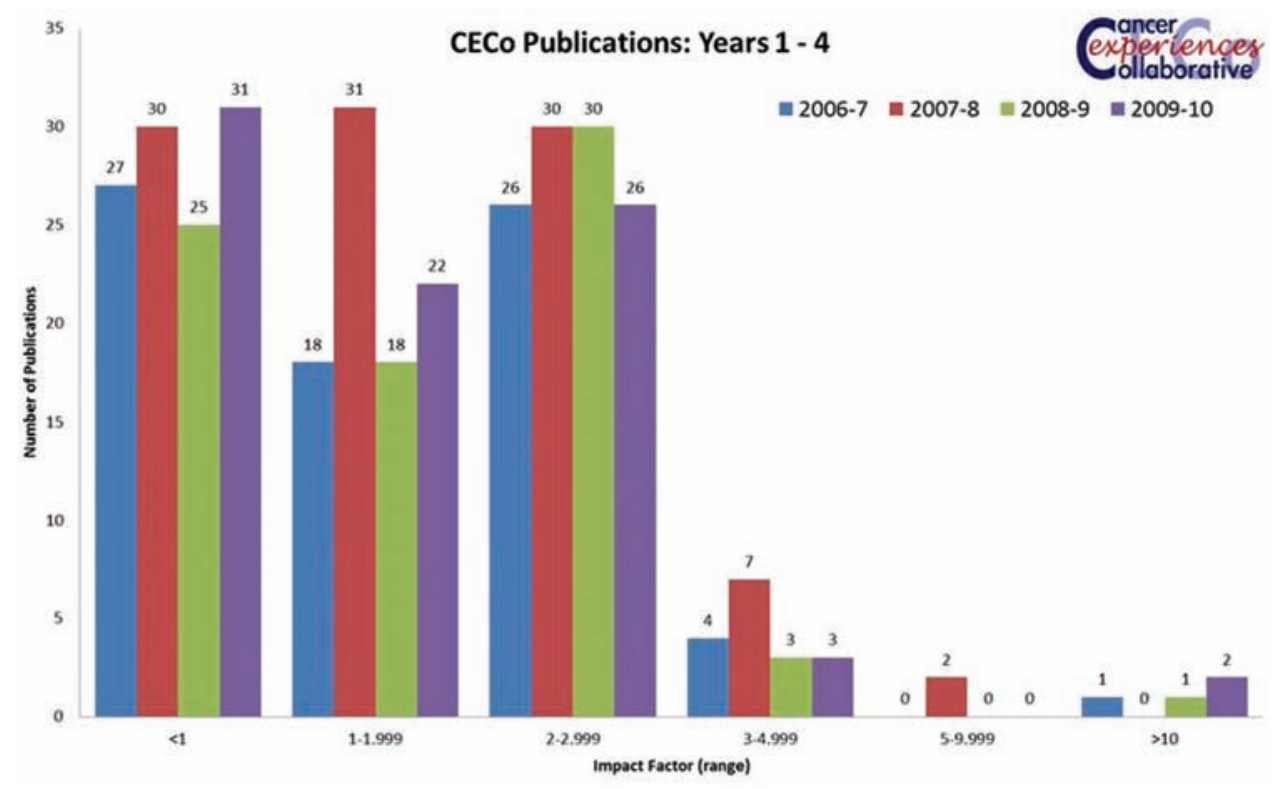

Figure 2 Cancer Experiences Collaborative publications: Years 1-4. 
community of researchers and academic disciplines which strengthened links to practice. Over 100 people from more than 20 different academic and clinical backgrounds, as well as service users, have been actively engaged in activities across CECo's three research themes. As a result, CECo has generated a critical mass of experienced research groups and researchers with international level performance in supportive and palliative care research. Since 2006, over 14 people have been actively involved in the organisation, management and leadership of CECo activities. These collaborative activities have resulted in significant achievements in each research theme, manifest in the increasing volume of dissemination activities, and the publication of 337 papers in clinical and academic journals. Figure 2 demonstrates that the majority of publications are in journals with impact factors of less than 5, perhaps indicating the early stage of development of this field.

This critical mass of researchers enabled the delivery of ambitious, and clinically meaningful, research. In the first 3 years, the Collaborative generated additional grant income of $£ 5.5$ million for new studies, which have either arisen directly from CECo or benefited from CECo's support.

The commitment to different perspectives has also resulted in the generation of research relevant to practice, and the enhancement of practitioners' understanding of research. Grants for large scale, high quality studies concerned with patient needs have been received from a wide range of funders including the Medical Research Council, the Economic and Social Research Council, the Department of Health, Macmillan Cancer Support and the National End of Life Care programme. Interdisciplinary research studies in the areas of innovative approaches to complex symptoms and of planning for the care of older adults towards the end of life, have focused on nonpharmacological interventions, assessment methods for complex symptoms, end of life decision making, public attitudes to and public education for end of life care, carer support, service evaluation and care homes. An additional focus has been on improving research methodologies and providing academic expertise to researchers across the other themes, resulting in a number of publications, including an annotated bibliography of narrative methods in supportive and palliative care. ${ }^{7}$ More recently, our methodological studies have focused on challenges in recruiting patients into end of life care studies.

In addition, while it is too soon to assess the full impact, the work of CECo has begun to make an important contribution to improving the illness experience for patients and their families through its contribution to policy, for example, the National Health Service (NHS) End of Life Care Strategy, ${ }^{8}$ responses to the Department of Health/Macmillan National Cancer Survivorship initiative, ${ }^{9} 10$ and the Family Carers in Palliative Care white paper. ${ }^{11} 12$ CECo is also influencing practice by engaging clinicians in research and, conversely, embedding researchers more within clinical practice. Two key objectives of the National Institute for Health Research Service Delivery and Organisation programme ${ }^{13}$ were to develop capacity in the managerial community for accessing, appraising and using research evidence, and to encourage greater engagement, linkage and exchange between the local research producers (usually universities) and potential local research users within the NHS. CECo's research has provided a significant evidence base, and is a model for collaborative engagement between universities and local research users, including clinicians in different supportive and palliative care settings. It is also having an impact on families and carers who are central to the cancer trajectory yet are often marginalised.
Enabling academics to work together in multi-scientific disciplinary groups, alongside encouraging clinicians and users to participate was, however, a challenging and difficult task requiring substantial effort. In particular, three significant threats to cohesion needed careful attention. The first of these arose from the pressures associated with academic convention where 'success' is predicated on individual performance and output, returnable through the appraisal process of the UK university research quality framework (http://www.hefce. ac.uk). This encourages researchers and institutions to be competitive, an attitude that works against collaborative partnerships and can lead to perceived inequity between institutions. Crossing the boundaries between disciplines and institutions was, therefore, a daunting task. Moreover, other aspects of UK university culture and structure often militate against alliance building: academic disciplines value different research methodologies and have conflicting expectations regarding scholarship, while university departments, including those in the Collaborative, normally compete against each other for research funding, and grant spend contributes to performance in the research assessment metrics (http://www.hefce.ac.uk). Second, partnerships, experienced at times as a diversion from one's own research interests, took individuals out of their comfort zone, while helping others to improve their grants took 'valuable' time from senior researchers' own work and interests. Third, while the aim of the Collaborative was to create an equal partnership between the major partners, a number of factors militated against this and required careful management to resolve. For example, over the 5 -year period, funding did not always follow staff movement, as a result of which the share of resource became unequally distributed. Research staff changes, often a result of short-term funding, had the potential to threaten group and Research Theme cohesion and required skilled leadership and team development to maintain. Nonetheless, through the exercise of effective leadership, new multi-scientific disciplinary groups of people were brought together, and the integral contribution to decision making of cancer patients and their carers was ensured. What remains uncertain is how to demonstrate and validate the added value of collaborative working over individual researcher effort, and provide evidence of the achievement of goals that are less amenable to the collection of measurable data. Whether collaboration can improve impact remains to be seen.

\section{Capacity building}

One of the key aims of CECo was to build research capacity in supportive and palliative care research by providing opportunities for a new generation of researchers to develop their expertise and skills (box 2). CECo made a decision to focus on developing clinicians and researchers at the early stages of their career, and each of the CECo Research Theme groups made a considerable contribution to this.

Two important benefits of CECo's work have emerged. First, there has been a consistent development of the span of individual (academic, clinician and user) researcher expertise in supportive and palliative care. In addition to the skills developed through involvement with all stages of research studies under the leadership of experienced researchers, individual research expertise has been developed through introductory research methods workshops and the award of nine CECo research scholarships to clinicians, which for an investment to date of $£ 90000$ has resulted in 12 peer-reviewed publications and grant capture. In addition, we conducted research master classes, and mentorship of novice researchers (particularly in 
hospices) through doctoral studies and postdoctoral fellowships, the appointment of nine research fellows, and the identification of 'rising stars' among senior lecturers and readers. Moreover, there have been increasing links with international scholars and research initiatives. For example, a joint workshop with researchers from The Netherlands and Belgium led to the development of a number of grant proposals, and strengthened epidemiological/public health expertise leading to funding for an international study on the perspectives of older people on end of life care. ${ }^{14}$ Second, the development of senior researchers in supportive and palliative care has been fostered. Alongside research and collaborative skills, leadership capacity in senior researchers has been encouraged through investment in leadership training with expert facilitators, and devolving budgets to theme leaders who have learnt to inspire and motivate their teams, manage people from different backgrounds with motivation and skill, and resolve conflicts as they arise.

Again, this has been a labour intensive activity as there has been little institutional recognition for the work within the Collaborative, especially that taking place outside an individual's institution. In addition, for some, skills have been enhanced and careers improved, while for others, the investment yielded little benefit. Capacity building has been patchy, with less engagement from medical professionals than anticipated. The reasons for this are uncertain: clinicians may not be released from their duties or they may lack other forms of support. Hospice doctors may also have been uncertain about how these more social science research-orientated awards would benefit their practice or contribute to their career. In addition, it takes longer to demonstrate the impact of this investment in young researchers and, perhaps most disappointingly, there has been an uncertain 'translation' of effort with non-active researchers (eg, through research methods workshops) becoming active researchers. Nevertheless, there have been opportunities for a

Box 2 The contribution of the Research Theme groups to capacity building

Developing new methodologies and approaches to address clinical challenges in supportive and palliative care research (including how best to meet the needs of patients, their families and carers; increase research capacity)

- Planning and coordinating activities within and across working groups through regular meetings

- Hosting 'State of the Science' meetings that brought together national and international supportive and palliative care researchers to appraise evidence, and devise and develop new areas of research

- Supporting and expanding the development of both new researchers and new research, eg, through $\mathrm{PhD}$ supervision and postdoctoral workshops

- Developing links between teams and disseminating opportunities for participation in research studies

- Hosting a series of workshops on research methods designed to address the needs of researchers across the spectrum of experience

- Operating a research scholarship scheme offering competitive grants of $£ 10000$ to clinicians to develop their research and scholarship skills under the mentorship of senior CECo research staff

Involving the wider public and user community new generation of researchers to develop their expertise and skills in supportive and palliative care research including those of leadership, and a new generation of capable researchers in supportive and palliative care has been fostered.

\section{User involvement}

One of CECo's outstanding achievements has been the commitment to involving patients and carers, ${ }^{15}$ and a major benefit has been the important contribution users have made to research proposals. In this respect, CECo has broken new ground by giving patients and their families and other users the opportunity to become integral to the research process through their involvement in all stages of research from planning through to dissemination. In addition, research partners offered advice on CECo scholarship awards, had abstracts accepted at NCRI and other conferences, submitted research proposals in their own right on topics such as friendship in cancer, and championed the work of the Collaborative.

User involvement, however, was also not without challenges. The involvement of patients and families and members of the public as research partners, where 'power-sharing' and shifting of control had the potential to feel threatening to professionals and academics, needed sensitive handling, and variable use has been made of users across the Collaborative, with not all researchers being able to make best use of the enormous resource that research partners represented. User involvement required a clarification of what this meant in practice and the development of a new view of citizenship by academics and professionals, challenging the Collaborative to consider novel ways of involving those who were, for example, too ill to attend meetings, or who had little experience of expressing themselves in public meetings. Furthermore, there were costs in involving users, in terms of subsidy and investment. For example, funding was required for training, conference registration, travel expenses and meeting hospitality, and the real costs of user involvement were often hidden.

Nevertheless, user involvement has added an important dimension to the work of CECo and has contributed to meeting CECo's aims of developing new methodologies and addressing clinical challenges in supportive and palliative care, including how best to meet the needs of patients and their families and carers.

\section{RECOMMIENDATIONS FOR FUTURE COLLABORATIVES}

From our experience of this "unnatural but interesting and important experiment", ${ }^{16}$ we would like to offer the following recommendations for researchers embarking on a similar collaboration. As a result of our experience there are a considerable number of lessons that have been learnt that may be of benefit to those setting up their own research collaboratives.

\section{Develop structures for good leadership and cross-institutional management}

The importance of good leadership and management structures cannot be overemphasised. The need to build and maintain trust with all those involved in a collaborative, and with their respective institutional managers, paves the way for smoother relationships and establishes a foundation for dealing with the issues and tensions that will inevitably arise.

Investing time and effort in the first year, and tackling issues of funding and resources, and cross-institutional management structures at an early stage, will strengthen the structural base of the collaborative and underpin the creative, research 
developments and activities. Similarly, trying to predict and pre-empt these tensions, for example, through activities that foster team-building and trust, will reap benefits, while introducing collegiate decision-making based on a shared vision, and being prepared to negotiate and re-negotiate these as issues arise, will strengthen confidence in a collaborative, rather than solely individual, research activity.

\section{Negotiate and communicate extensively, including clarifying the purpose and aims of the collaborative}

Negotiation is important in three different spheres: within the collaborative, within and between institutions, and with the wider world. Extensive and early negotiation to bring people together from diverse institutions to work in groups within and across themes, and encouraging individuals to place value on the different disciplinary perspectives, on the contribution of users as research partners, and on the achievements of the collaborative while recognising the extent of contributions made by its individuals, will help build a wider collective identity, a sense of cohesion, and a commitment to a wider vision. The development of a website will provide a valuable resource for developing and maintaining communication across a variety of groups and institutions.

\section{Develop strategies for evaluating the success of the collaborative}

While CECo has been able to audit its achievements in terms of outputs (eg, the numbers of grants awarded, the numbers of papers published, the numbers of attendees at training events), we are still seeking ways of evaluating success in terms of meeting the original aims, which are less amenable to measurement. Evaluating the 'added value' of enhanced research - with more good quality research data now available, for example, for systematic review and the development of clinical guidelines - and measuring the impact of the increase in the number of experienced researchers in supportive and palliative care over time, is more challenging. Identifying and implementing innovative methods to achieve this, and evaluating the collaborative and its impact, is important not only to those within the scheme, but also to those who fund it.

\section{THE FUTURE OF CECO}

Supportive and palliative care remain policy, practice and research priorities, but much still needs to be done. The activities of CECo have resulted in significant benefits. As well as the increase in good quality research studies that has led to the availability of a significant number of peer-reviewed academic and professional papers, the intellectual stimulation, intelligence sharing and learning from other disciplines and between academics, clinicians and users, has contributed to raising the standards of supportive and palliative care research. Despite the challenges, CECo - as a collaboration of academics, clinicians and patients and families - has made a substantial contribution to extending and improving the evidence base for policy and practice decisions in supportive and palliative care, and the model of research collaboration pioneered by CECo has attracted increasing international interest. It has been recognised that models of governance, leadership, collaborative research, research capacity and user involvement developed by the CECo team have wider applicability beyond supportive and palliative care research, and beyond the UK.
However, the future of CECo is fragile. Despite the overall praise for the success of the Collaborative and the need for a better evidence base for clinicians, we recognise that we are now moving into a different, and challenging, economic climate from when CECo began. This will make our own, and future collaboratives, very difficult to develop and sustain. Resources are increasingly limited: major funders have withdrawn from the field, there is a reduction in charitable giving and there are changes within the UK university environment that increasingly favour inter-institutional competition. As a result, there are increasing pressures both on the statutory sources and other funding sources that remain. It was therefore with disappointment, but not surprise, that we received the news that NCRI is unable to offer continued funding for CECo.

Other changes are anticipated within the NHS, with major commissioning responsibilities being devolved to general practitioners. ${ }^{17}$ It is argued that an important aspect of commissioning should be to help ensure the explicit commitment to best practice, defined by evidence-based effectiveness and efficiency, ${ }^{18}$ and there is "an urgent need for more evidence, including information on cost-effectiveness and evaluations of new models of care, to give commissioners the confidence to change the way in which services are delivered locally". ${ }^{19}$ It is imperative, therefore, that the lessons learnt from CECo are not lost, in particular the capacity to work collaboratively with academics, clinicians and patients and families to generate sufficient funds to undertake large-scale, interdisciplinary, studies that provide evidence to inform policy and underpin practice in supportive and palliative care.

Contributors All authors conceived and designed the article. SP and LR drafted the article and all authors revised it critically for important intellectual content and gave final approval of the version to be published.

Funding Financial support from the National Cancer Research Institute partnership consortium is gratefully acknowledged.

\section{Competing interests None.}

Provenance and peer review Not commissioned; externally peer reviewed.

\section{REFERENCES}

1. Department of Health. End of Life Care Strategy: Second Annual Report. London: Department of Health, 2010

2. National Cancer Research Institute. Supportive and Palliative Care Research in the UK: Report of the NCRI Strategic Planning Group on Supportive and Palliative Care. London: NCRI, 2004

3. National Cancer Research Institute. 3 Year Progress Report 2001-2004. London: NCRI, 2004.

4. Collaborative Group on Hormonal Factors in Breast Cancer. Breast cancer and breastfeeding: collaborative reanalysis of individual data from 47 epidemiological studies in 30 countries, including 50302 women with breast cancer and 96973 women without the disease. Lancet 2002;360:187-95.

5. National Cancer Research Institute. Prostate Cancer Collaboratives. NCRI, 2000. http://www.ncri.org.uk/default.asp?s $=1 \& p=7 \& s s=3$ (accessed 5 November 2010)

6. Beresford P. Service users, social policy and the future of welfare. Crit Soc Pol 2001;21:494-512.

7. Rolls L, Payne S, Brown J. Narrative Methods in Supportive and Palliative Care: An Annotated Bibliography. Observatory Publications, Lancaster University 2009.

8. Department of Health. End of Life Care Strategy: Promoting High Quality Care for All Adults at the End of Life. Department of Health, 2008.

9. Department of Health/Macmillan. National Cancer Survivorship Initiative. Department of Health, 2008. http://www.dh.gov.uk/prod_consum_dh/groups/dh_digitalassets/@ dh/@en/documents/digitalasset/dh_088884.pdf (accessed 15 0ctōber 2010).

10. Richardson A, Addington-Hall J, Stark, D, et al. Determining Research Priorities for Cancer Survivorship: Consultation and Evidence Review. 2009. http://www. compasscollaborative.com/pdf/Richardson\%20et\%20al\%202009\%20Cancer\%20 Survivorship\%20research\%20priorities\%20FINAL\%209-3-2010.pdf laccessed 15 October 2010).

11. Payne $\mathbf{S}$. White Paper on improving support for family carers in palliative care: part 1. Recommendations from the European Association for Palliative Care (EAPC) Task Force on Family Carers. Eur J Pall Care 2010;17:238-45. 
12. Payne S. EAPC White Paper on improving support for family carers in palliative care: part 2. Recommendations from the European Association for Palliative Care (EAPC) Task Force on Family Carers. Eur J Pall Care 2010;17:286-90.

13. National Institute for Health Research. NIHR Service Delivery and Organisation Programme. 1999. http://www.sdo.nihr.ac.uk (accessed 10 November 2010).

14. Pleschberger S, Seymour J, Payne S, et al. Interviews on end of life care with older people: reflections on six European studies. Qual Health Res 2011; (In Press).

15. Wilson R. CECo's research partners. CECo News 2007;1:2. http://www.ceco.org uk/resourcedocs/jan07.pdf (accessed 29 April 2010).

16. Payne S, Addington-Hall J, Richardson A, et al. Supportive and palliative care research collaboratives in the United Kingdom: an unnatural experiment? Palliat Med 2007;21:663-665.
17. Department of Health. Equity and Excellence: Liberating the NHS. Department of Health, 2010. http://www.dh.gov.uk/prod_consum_dh/groups/dh_digitalassets/@ dh/@en/@ps/documents/digitalasset/dh 117794.pdf laccessed 15 0ctober 2010).

18. Kirk $\mathbf{S}$. Demonstrating the value of new models of care and commissioning. In: Addicott R, Ashton R, eds. Delivering Better Care at End of Life: The Next Steps. London: Kings Fund 2009;27-9. http://www.kingsfund.org.uk/publications/leeds castle eolc.html (accessed 16 October 2010).

19. Addicott R. Ashton R. Discussion. In: Addicott R, Ashton R, eds. Delivering Better Care at End of Life: The Next Steps. London: Kings Fund 2009;37-47. http://www.kingsfund.org.uk/publications/leeds_castle_eolc.html (accessed 16 October 2010). 
BMJ Supportive \& Palliative Care

\section{Benefits and challenges of collaborative research: lessons from supportive and palliative care}

Sheila Payne, Jane Seymour, Alex Molassiotis, et al.

BMJ Support Palliat Care 2011 1: 5-11

doi: 10.1136/bmjspcare-2011-000018

Updated information and services can be found at:

http://spcare.bmj.com/content/1/1/5.full.html

These include:

References This article cites 6 articles, 1 of which can be accessed free at: http://spcare.bmj.com/content/1/1/5.full.html\#ref-list-1

Email alerting Receive free email alerts when new articles cite this article. Sign up in service the box at the top right corner of the online article.

\section{Collections}

Articles on similar topics can be found in the following collections

Journalology (1367 articles)

End of life decisions (geriatric medicine) (1477 articles)

End of life decisions (palliative care) (1511 articles)

Hospice (1708 articles)

End of life decisions (ethics) (1484 articles)

Notes

To request permissions go to:

http://group.bmj.com/group/rights-licensing/permissions

To order reprints go to:

http://journals.bmj.com/cgi/reprintform

To subscribe to BMJ go to:

http://group.bmj.com/subscribe/ 